\title{
Possibilidades do ensino das lutas na escola: uma pesquisa-ação com professores de educação física
}

\author{
Possibilities of school fighting teaching: \\ an action research with physical education teachers \\ DOI: http://dx.doi.org/10.36453/2318-5104.2018.v16.n1.p99
}

\section{Bernhardt Hegele, Fernando Jaime González, Robson Machado Borges}

Universidade Regional do Noroeste do Estado do Rio Grande do Sul (Unijuí)

\section{RESUMO}

Esta pesquisa buscou verificar quais são as consequências de uma experiência de formação colaborativa, nas concepções de professores acerca da abordagem das lutas nas aulas de educação física escolar. Para tanto, operou-se metodologicamente com a realização de uma pesquisa-ação com quatro docentes de Educação Física que atuam em escolas públicas no interior do Rio Grande do Sul. Os professores, juntamente com um dos pesquisadores, constituíram um grupo de estudos que se reuniu semanalmente em oito encontros, com o intuito de refletir sobre a abordagem das lutas na educação física escolar. Os resultados indicam que, inicialmente, os professores não se sentiam em condições de tematizar as lutas na escola. Especialmente, porque não tiveram um componente curricular específico em sua formação inicial. No entanto, após a realização do estudo, os docentes compreenderam que é possível trabalhar com as lutas nas aulas de educação física. Os principais fatores que geraram essa alteração foram o estudo dos jogos de lutas e sua classificação com base nas distâncias, a produção de tarefas durante os encontros e a vivência corporal nas reuniões.

PALAVRAS-CHAVE: Lutas; Educação Física escolar; Pesquisa-ação.

\section{ABSTRACT}

This research sought to verify the consequences of a collaborative training experience, in the conceptions of teachers about the approach of the struggles in the School Physical Education classes. For that, it was operated methodologically with the accomplishment of an action research with four physical education teachers who work in public schools in the interior of Rio Grande do Sul (Brazil). The teachers, together with one of the researchers, constituted a study group that met weekly in eight meetings, in order to reflect on the approach of the struggles in physical school education. The results indicate that, initially, the teachers did not feel able to thematize the struggles in the school. Especially, because they did not have a specific curricular component in their initial formation. However, after the study, teachers understood that it is possible to work with the struggles in physical education classes. The main factors that led to this change were the study of the games of fights and their classification based on distances, the production of tasks during the meetings and the corporal experience in the meetings.

KEYWORDS: Fights; School Physical Education; Action research. 


\section{INTRODUÇÃO}

As lutas corporais ${ }^{1}$ fazem parte da cultura corporal do brasileiro e, atualmente, são bastante difundidas pelos meios de comunicação (televisão, jornais, rede mundial de computadores, entre outros). Os microdados do suplemento de "Práticas de esporte e atividade física", da Pesquisa Nacional por Amostra de Domicílios (IBGE, 2017) permitem estimar que, entre as pessoas que declaram praticar esporte ou atividade física, 1,7\% praticam "lutas/artes marciais".

Nessa linha, os eventos de luta na mídia, as propagandas das academias e dos clubes, os inúmeros filmes com a temática, são cada vez mais comuns. Além de seu caráter contemporâneo e midiático, Rufino e Darido $(2015$, p. 22) destacam a característica histórica e cultural das lutas afirmando que "[...] são práticas historicamente importantes e que acompanharam os seres humanos ao longo do tempo, sendo umas das mais elementares manifestações [da] cultura".

Nesse sentido, entendemos que a escola - mais precisamente a Educação Física - precisa assumir a responsabilidade de tematizar essa prática corporal histórica, como tema de ensino, conforme consta nos Parâmetros Curriculares Nacionais (BRASIL, 1998), na Base Nacional Comum Curricular (BNCC, 2017) e é defendido por vários autores (BETTI, 2013; GONZÁLEZ; FRAGA, 2012, entre outros). No entanto, o ensino das lutas nas aulas de Educação Física escolar é algo bastante raro, uma vez que a maioria dos professores não o desenvolve (MATOS et al., 2015; RUFINO; DARIDO, 2011). Com isso, "[...] há um distanciamento entre o que é previsto para se ensinar e o que é efetivamente ensinado nas escolas" (MATOS et al., 2015, p. 119), mesmo com o aumento das investigações sobre as lutas e as artes marciais nos últimos anos (HEROLD JÚNIOR, 2016).

Desse modo, as lutas se constituem como um dos temas da Educação Física escolar que encontram maior resistência por parte dos professores, havendo preconceitos em relação ao seu ensino. Segundo Matos et al. (2015), os preconceitos se relacionam com a falta de espaço, vestimentas e materiais adequados e, também, pela associação às questões de violência. Sobre isso, Rufino e Darido (2015, p. 57) afirmam que "[...] os preconceitos estão cristalizados, o que torna ainda mais difícil significá-los. Nesses casos, será necessário 'lutar' para quebrar determinados paradigmas que possam prejudicar o ensino das lutas na escola".

Alguns desses preconceitos, relacionam-se com o fato de a formação inicial encontrar dificuldades para assegurar aos professores condições efetivas de trabalho com essa temática. Afinal, "apesar da previsão curricular oficial e da inclusão da discussão sobre lutas na formação de professores [...]" (RUFINO; DARIDO, 2015 , p. 120), muitos docentes alegam que não tiveram um componente curricular acerca do assunto no período de graduação em Educação Física. Outros, mesmo tendo, não se sentem preparados para desenvolver o seu ensino para os alunos (MATOS et al., 2015).

Sobre as fragilidades da formação inicial em Educação Física, Castellani Filho (2011) entende que a maioria dos cursos ainda tem uma lógica de formação profissional do século passado, o que dificulta uma evolução da área no Brasil. Na mesma linha, Zeichner e Diniz-Pereira (2005, p. 66) alertam para os limites da graduação, apontando que "não podemos confiar apenas no conhecimento gerado na universidade para formação profissional [...]". Segundo os referidos autores, é possível "[...] no máximo formar profissionais para iniciarem sua prática" (ZEICHNER; DINIZ-PEREIRA, 2005, p. 66).

A quase inexistência do ensino das lutas nas aulas de Educação Física ganha um reforço na pouca produção científica sobre o tema. Num estudo realizado por Correia e Franchini (2010), os autores constataram que dos 2.561 trabalhos acadêmicos publicados em periódicos nacionais, entre 1998 e 2008, apenas 75, ou seja, menos de três por cento, abordavam a temática das lutas.

Neste cenário, perece fundamental a realização de investimentos que contribuam para uma alteração na concepção dos professores sobre o ensino das lutas na Educação Física escolar. Particularmente, a pesquisaação tem sido apontada como um tipo de investigação bastante eficaz para o estudo com professores (BETTI, 2013; TRIPP, 2005). No entanto, em relação ao tema "lutas", parecem raros os estudos colaborativos que se

${ }^{1}$ Segundo Correia e Franchini (2010, p. 1) "o termo 'Luta' de forma recorrente e dinâmica implica um investimento diversificado de representações e significados, o que por sua vez, Ihe confere uma dimensão polissêmica. Como exemplificação, temos as noções de lutas de classe, dos trabalhadores, pelos direitos da mulher, pela vida e outros mais". Neste estudo, utilizamos o termo luta nos referindo a lutas corporais que são práticas geralmente individuais e que apresentam características de enfrentamento físico direto entre adversários, com regras que conduzem as ações realizadas em um ambiente estável e sem interferências naturais (RUFINO; DARIDO, 2015). 
dedicam a tentar uma alteração na situação atual ${ }^{2}$. Inquietados por esse contexto, realizamos uma investigação que tem como objetivo verificar quais são as consequências de uma experiência de formação colaborativa, nas concepções de professores acerca da abordagem das lutas nas aulas de educação física escolar.

\section{MÉTODOS}

A presente pesquisa está pautada em uma abordagem qualitativa. Especificamente, trata-se de uma pesquisa-ação, "[...] pesquisa na qual as pessoas envolvidas têm participação ativa, e na qual há uma exigência de conhecimento a ser produzido" (BETTI, 2010, p. 142). De acordo com Thiollent (2011, p. 20), trata-se de

[...] um tipo de pesquisa social com base empírica que é concebida e realizada em estreita associação com uma ação ou com a resolução de um problema coletivo e no qual os pesquisadores e participantes representativos da situação ou do problema estão envolvidos de modo cooperativo ou participativo.

Os sujeitos participantes deste estudo foram quatro professores, com formação em Educação Física, que atuam em escolas de uma cidade da região Noroeste do estado do Rio Grande do Sul. Os educadores, dois homens e duas mulheres, juntamente com um dos pesquisadores, formaram um grupo de estudos. A seguir descrevemos um breve histórico dos docentes.

- Professor A3: 44 anos, concluiu o curso de graduação em 1998. Atua como docente há 15 anos. Tem mestrado em Ciências da Educação.

- Professora B: 29 anos, concluiu o curso de graduação em 2010. Atua como docente há dois anos.

- Professora C: 38 anos, concluiu o curso de graduação em 2000. Tem especialização em Educação Física escolar e mestrado em Ciências do Movimento Humano. Atua como docente há dez anos.

- Professor D: 33 anos, concluiu o curso de graduação em 2009. Atua como professor há três anos. Possui especialização em Fisiologia do Exercício.

Quadro 1. Temas estudados nos encontros ${ }^{4}$.

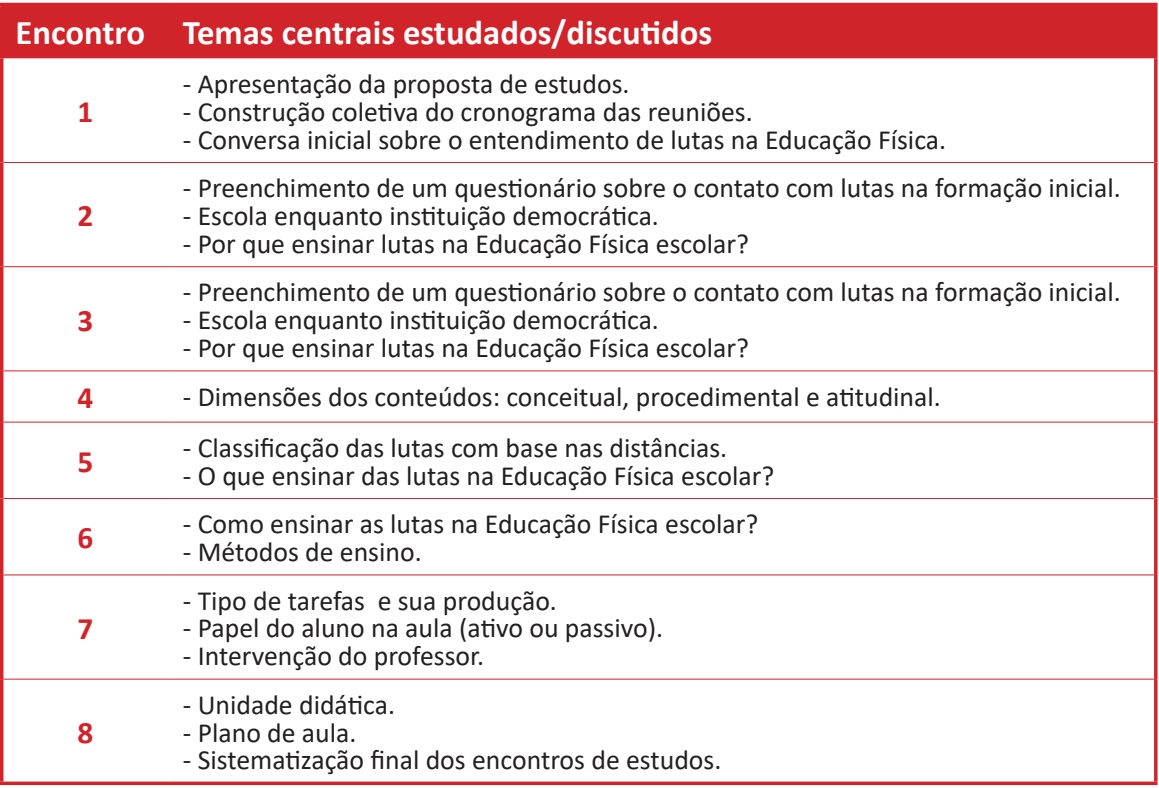

\footnotetext{
${ }^{2}$ A dissertação de mestrado de Rufino (2012b) é um dos escassos estudos.

${ }^{3}$ Visando a preservar a identidade dos participantes da investigação, seus nomes foram substituídos pelas letras A, B, C e D. Cabe ressaltar que os professores autorizaram a divulgação dos resultados da pesquisa mediante assinatura do Termo de Consentimento Livre e Esclarecido.
} 
O processo de investigação ocorreu durante oito encontros do grupo de estudos, uma vez por semana, com duas horas de duração cada dia. Durante as reuniões se procurou criar um clima de confiança, na tentativa de que os docentes se sentissem confortáveis em dialogar e expressar suas opiniões sobre os assuntos relacionados ao ensino das lutas na Educação Física escolar. Especificamente, os integrantes do grupo se reuniam numa sala e dialogavam sobre suas concepções acerca do desenvolvimento das lutas como tema de ensino da Educação Física. Para facilitar a compreensão do que foi realizado, apresentamos o Quadro 1 com a síntese dos assuntos tratados nos encontros.

Como recursos para a produção de dados foram utilizados: a) as gravações dos encontros do grupo de estudos, posteriormente transcritas na íntegra; b) anotações e proposições didáticas elaboradas pelos docentes, recolhidas ao final das reuniões; c) um questionário sobre o contato com lutas na formação inicial; d) registros sobre o desenrolar dos encontros, realizados no diário de campo do pesquisador.

\section{RESULTADOS E DISCUSSÃO}

Para aferir os resultados do estudo, utilizamos uma análise de conteúdo com base em Silverman (2009). Este autor entende que nesse tipo de análise os pesquisadores estabelecem uma série de categorias definidas, de modo que, na pesquisa qualitativa, utilizam-se trechos e recortes não tabulados que ilustram categorias em especial.

Nessa perspectiva, organizamos os resultados em um conjunto de três categorias: (1) o desconhecimento sobre o ensino das lutas; (2) a relação entre o entendimento do papel da Educação Física na escola e o sentido atribuído pelos professores aos assuntos/conteúdos estudados; (3) a mudança de concepção dos docentes sobre o ensino das lutas na Educação Física escolar.

Acerca da primeira categoria, interpretamos que os professores não se consideravam em condições de desenvolver o tema lutas nas aulas de Educação Física escolar, como se identifica na seguinte fala: "Não tenho ideia de como ensinar lutas" (Prof. B). O principal motivo apontado por eles é que não tiveram um componente curricular sobre lutas na formação inicial, pois entendem que seria essencial para ter ao menos uma base de como trabalhar com essa temática na escola. Esse resultado é semelhante ao encontrado por Matos et al. (2015), pois dos 26 entrevistados em seu estudo a maioria não cursou um componente curricular relacionado as lutas na formação inicial.

Assim, é possível pensar que, em boa medida, a graduação não lhes ofereceu condições efetivas para o ensino dessa temática, como se percebe nas seguintes locuções: "Metodologia das lutas, agora faz parte do currículo, mas na minha época era optativa, então você não tem um conhecimento das lutas, eu nunca ia dar aula de lutas, se eu nunca tive uma vivência, nunca soube ensinar" (Prof. C); "Essa proposta é bacana, é interessante... Eu consegui só agora vivenciar com nosso grupo de estudos as lutas" (Prof. B). Esse achado é idêntico ao encontrado por Lima (2018), uma vez que o principal motivo apontado pelos professores participantes de sua pesquisa para não abordar lutas em suas aulas, vincula-se ao fato de não terem cursado uma disciplina em sua formação inicial que ofereceu saberes suficientes para o ensino na escola. Na mesma linha, Saldanha (2018) identificou que apesar de os docentes considerarem importante o ensino das lutas na Educação Física, eles não desenvolvem o tema em suas aulas, pois não se sentirem preparados, apontando que a graduação não lhes ofereceu os conhecimentos necessários.

Outras evidências sobre isso, são as respostas dos professores no questionário preenchido no segundo encontro de estudos, em questões relacionadas ao contato com o tema lutas na graduação em Educação Física, como se observa no Quadro 2.

Analisando a segunda categoria, foi possível identificar que o sentido atribuído pelos professores aos assuntos estudados nos encontros tem relação direta com o entendimento deles sobre o papel da Educação Física na escola. Dessa forma, para os docentes A e C - que têm atuações pautadas no entendimento de que a

${ }^{4}$ Os assuntos foram propostos com base em González e Bracht (2012), González e Fensterseifer (2009, 2010), Rufino (2012a) e Rufino e Darido (2015). Também, levamos em consideração a sugestão de Matos et al. (2015, p. 117): "[...] que as formações privilegiem as abordagens estruturadas em similaridades e nos princípios das Lutas".

${ }^{5}$ González e Bracht (2012, p. 77) definem tarefa como "[...] o trabalho, ou atividade indicada pelo professor (eventualmente auto sugerida) a ser executada pelos alunos, que envolve dificuldades, esforço e/ou prazo determinado". 
Educação Física é um componente curricular responsável por tratar dos diversos temas da cultura corporal de movimento e por uma proposta de trabalho organizada em conteúdos curriculares e unidades didáticas - os assuntos estudados foram compreendidos como mais um elemento para inserir na pluralidade de temas que eles já desenvolvem, visando o aprendizado dos alunos.

Quadro 2. Respostas dos professores a questões relacionadas ao contato com o tema lutas na graduação em Educação Física.

\begin{tabular}{|l} 
Professor \\
Respostas dos professores \\
A \\
3) Na sua formação universitária existia uma disciplina específica sobre lutas? Não. \\
4) Como foram trabalhados os conteúdos de lutas na sua graduação? (...) \\
5) O seu curso de graduação ofereceu condições para que você inclua a luta em suas aulas? Por quê? (...) \\
B \\
3) Na sua formação universitária existia uma disciplina específica sobre lutas? Não fiz nenhuma disciplina de \\
lutas. \\
4) Como foram trabalhados os conteúdos de lutas na sua graduação? Não foram trabalhados, pois não fiz \\
nenhuma disciplina, mas lembro que tinha como optativa. \\
5) O seu curso de graduação ofereceu condições para que você inclua a luta em suas aulas? Por quê? Não sei. \\
Porque como era optativa não cheguei a fazer esta disciplina. \\
C \\
$\begin{array}{l}\text { 3) Na sua formação universitária existia uma disciplina específica sobre lutas? Não. } \\
\text { 4) Como foram trabalhados os conteúdos de lutas na sua graduação? (...) } \\
\text { 5) O seu curso de graduação ofereceu condições para que você inclua a luta em suas aulas? Por quê? (...) }\end{array}$ \\
(3) Na sua formação universitária existia uma disciplina específica sobre lutas? Optativa apenas. \\
4) Como foram trabalhados os conteúdos de lutas na sua graduação? Como Disciplina optativa, a qual não \\
cursei. \\
5) O seu curso de graduação ofereceu condições para que você inclua a luta em suas aulas? Por quê? Sim, \\
ofereceu como optativa e não fazendo parte da grade curricular.
\end{tabular}

Ao contrário, os professores B e D têm uma visão diferente do papel da Educação Física na escola, pensam o componente curricular como um espaço de recreação sem o foco no aprendizado dos alunos. Eis uma fala nessa linha: "Eu topo sim participar do grupo, mesmo sabendo que não vou usar nas aulas, mas vai ser legal para aprender umas brincadeiras novas" (Prof. B). Nesse sentido, interpretamos que os docentes B e $D$ perceberam os assuntos estudados no grupo de estudos como um repertório de atividades para serem "aplicadas" nas aulas, descontextualizadas de uma unidade de ensino estruturada para desenvolver um tema específico.

Nessa perspectiva, parece necessário o cuidado ao desenvolver estudos colaborativos visando alteração de concepção de professores de Educação Física para não desvincular um tema estudado do sentido que os docentes atribuem ao componente curricular. A nosso ver, nesse estudo, a compreensão do papel dessa disciplina na escola influenciou a concepção sobre uma possível utilização dos assuntos estudados.

Na última categoria estabelecida, constatamos o acontecimento de uma mudança de concepção dos professores sobre o ensino das lutas na Educação Física escolar. Entendemos que os docentes aprenderam mais acerca das lutas do que sabiam antes do estudo. Os professores A e C, especialmente, compreenderam que é possível trabalhar com esse tema na escola numa perspectiva crítica e reflexiva, possibilitando assim o aprendizado dos alunos. Nesse sentido, pensamos que quatro fatores principais tiveram destaque nesse processo: 1) o estudo dos jogos de lutas; 2) o estudo da classificação das lutas com base nas distâncias; 3 ) a produção de tarefas durante os encontros; 4) a vivência corporal das lutas pelos professores durante as reuniões.

A produção de conhecimento conceitual dos docentes sobre das lutas começou a ocorrer a partir do momento em que foram estudados os jogos de lutas, como possibilidade de abordar aspectos universais dessa prática corporal ${ }^{6}$. Com isso, eles perceberam que é possível desenvolver as lutas como uma criação histórica da humanidade através de enfrentamentos corporais e não apenas com algumas modalidades específicas ${ }^{7}$

\footnotetext{
${ }^{5}$ Utilizamos o símbolo (...) para representar questões "em branco", uma vez que não foram respondidas pelos professores

${ }^{6}$ Como aponta Gomes (2008, p. 11), destacando aspectos vinculados à lógica interna, "[...] as Lutas dispõem de princípios condicionais (contato proposital, fusão ataque/defesa, oponente/alvo, imprevisibilidade e regras) determinantes para a compreensão e leitura da dinâmica interna de qualquer prática de Luta, que solicitam o pensamento tático e a criação de técnicas para solução dos problemas num combate".

${ }^{7}$ Segundo Gomes (2008, p. 11) "[...] o ensino fragmentado em modalidades na iniciação tende a restringir o universo de possibilidades inerentes aos
} 
(esportes de combate ${ }^{8}$ ), como se percebe na manifestação do professor D: "Até fica fácil pelas dinâmicas de fazer, porque antes, as lutas tu já pensa em soco e chute, em se machucar, daí tu pensa, não vou levar pra escola lutas se tu não consegue trabalhar, mas essas atividades são bem simples, bem lúdicas, daí tu já consegue trabalhar". Segundo Matos et al. (2015), alguns professores participantes do seu estudo entendem que atividades relacionadas às lutas estimulariam atitudes impróprias, como a agressividade.

Contudo, foi a partir do momento em que o grupo estudou a classificação das lutas com base nas distâncias e nas ações estabelecidas ${ }^{9}$, que os professores tiveram uma compreensão mais clara da possibilidade de trabalhar com o tema na Educação Física escolar, sem precisar ser faixa preta ou ter experiência com algum tipo de esporte de combate. Percebemos isso através das expressões e declarações dos professores, como por exemplo: "[...] ter a classificação das lutas pra mim foi o auge da coisa, do nosso estudo, no sentido de dar significado" (Prof. C); "Como é legal agora poder fazer essa distinção com essa classificação, daí já é outro, tu vai garantir uma de cada, pode trabalhar muito melhor" (Prof. A); "Nossa, a gente não tinha nem ideia de que as lutas podiam ser classificadas desse jeito" (Prof. A); "Bom, lutas também entram numa classificação, a classificação é essa, daí eu posso, qualquer luta que eu for trabalhar, a gente encaixa nessa classificação.... Agora eu já posso fazer uma unidade didática.... Bem legal assim" (Prof. C).

Essas falas indicam que a pesquisa começou a oferecer os frutos mais concretos, pontualmente a partir do estudo da classificação das lutas com base nas distâncias, ocorrido no quinto encontro. Matos et al. $(2015$, p. 124) defendem que classificações desse tipo "[...] permitem ao professor melhor sistematizar seu planejamento no sentido de abordar as Lutas partindo de seus princípios operacionais, envolvendo, desta forma, muitas modalidades diferentes, mas com características semelhantes". Assim, ao realizar outro trabalho nessa perspectiva acreditamos que esse conteúdo, em particular, poderia ser trabalhado mais cedo, despertando previamente o interesse e a própria evolução do conhecimento dos professores.

Na mesma linha, uma opção metodológica positiva que colaborou na mudança de concepção dos docentes foi solicitar que produzissem tarefas durante os encontros. $O$ fato de experimentar a proposição de atividades em grupo, de acordo com a classificação de lutas, como consta no Quadro 3, proporcionou um domínio maior sobre o tema. Essa ação pode gerar boas possibilidades para trabalhar com as lutas em suas aulas de educação física na escola.

Quadro 3. Produção de tarefas* durante os encontros.

\begin{tabular}{|c} 
Professor(a) Tarefas propostas pelos professores \\
Curta: Um de frente para o outro de joelhos. Vence a luta aquele que conseguir \\
apenas com as mãos desequilibrar o adversário colocando-o no chão, ou tirando \\
um dos joelhos do chão. \\
Média: Em pé um de frente para o outro. Vence a luta aquele que conseguir tocar \\
três vezes as costas do adversário. \\
Curta: Cada aluno num quadrado do tatame, agarram-se as mãos, um empurran- \\
do o outro, quem tirar o oponente do tatame ganha. \\
Média: Pega lenços: colocar o lenço atrás da bermuda, um tenta roubar do outro, \\
quem pegar mais ganha. \\
Curta: Briga de galo: Em duplas, frente a frente, agachados. Ao sinal devem \\
B \\
tentar desequilibrar o adversário com o uso das mãos, permanecendo sempre em \\
movimento (pequenos saltinhos). \\
Média: Varal: em duplas, cada um da dupla com um prendedor de roupa preso \\
na camiseta (ombros). Ao sinal o objetivo é retirar os prendedores do adversário. \\
Podem ser feitos de forma individual (contra grupo) cada um cuidando todos. \\
Curta: Dois a dois, em pé, cada aluno apoia as mãos no ombro do colega. Em de- \\
Cerminado sinal o aluno deve empurrar, utilizando apenas a força, o colega para \\
fora do espaço determinado. \\
Média: Dois a dois, os alunos frente um ao outro, ao sinal cada aluno deve tocar \\
com a mão o ombro do colega, e ao mesmo tempo não deixar que o colega toque \\
o seu ombro. Sendo ataque e defesa.
\end{tabular}

* Em função do limite de espaço desse texto, apresentamos apenas as proposições de tarefas para dois tipos de distâncias, conforme a classificação de Rufino e Darido (2015).

${ }^{8}$ González e Bracht (2012, p. 24) definem esportes de combate como "[...] disputas nas quais uns tentam vencer os outros por meio de toques, desequilíbrios, imobilização, exclusão de um determinado espaço e, dependendo da modalidade, por contusões, combinando ações de ataque e defesa (por exemplo: boxe, esgrima, jiu-jítsu, judô, karatê, luta, sumô, taekwondo etc.)".

${ }^{9}$ Em sua dissertação de mestrado, Gomes (2008) apresenta - de modo inovador no Brasil - um levantamento das classificações atribuídas às lutas, pautando-se nas ideias de diversos autores, principalmente de Espartero (1999). 
Um quarto fator que influenciou na alteração de concepção dos professores sobre o ensino das lutas na educação física escolar, foi a vivência corporal durante os encontros de estudo. A condição de eles desempenharem corporalmente tarefas em que precisavam realizar ações táticas e técnicas, visando o corpo do oponente para superá-lo, possibilitou uma melhor apropriação dos assuntos estudados conceitualmente, como manifesta o professor A: "Agora, tipo, lendo o livro e com essas práticas nos encontros, dá pra ter uma baita noção". De algum modo, a ideia de ensinar lutas passou a fazer sentido para os docentes. Como apontado em Borges (2014), se os professores precisam ser ensinados a ensinar, isso precisa ocorrer também na prática.

Nesse contexto, entendemos que após o estudo os docentes passaram a acreditar na possibilidade de trabalhar com o tema lutas na Educação Física escolar e demonstraram certo domínio a respeito dos assuntos discutimos nos encontros. Assim, ocorreu uma alteração do fato de que os professores não se sentiam preparados para desempenhar o ensino das lutas na escola, para o entendimento de que agora compreendem a possibilidade de se trabalhar com o tema em suas aulas. $O$ professor $A$, inclusive, realizou uma aula sobre lutas com seus alunos na escola em que atua, com base nas vivências corporais que o grupo de estudos teve no quinto encontro e relatou:

A turma de quinta, minha agora, fiz a aula daquele dia que nós fizemos lá... Foi bem tranquilo assim, expliquei os jogos de luta, de curta, média, longa distância, o que eles compreendiam de lutas e tal. Daí cada um deu a sua opinião, daí expliquei aquele resumo de lutas e fiz umas atividades práticas. Fiz aquela de colocar o colete atrás, daí essa eles gostaram mais [...].

Com isso, é possível pensar que professores que historicamente não desenvolvem a abordagem das lutas nas aulas de Educação Física escolar, podem passar a realizar tal ação se forem oferecidas condições efetivas para tanto. Dito de outro modo, a partir do momento no qual os docentes tomam contato com uma proposta para o ensino das lutas que faça sentido para eles, os professores têm condições - após um tempo de estudos - de trabalhar com um tema no qual não adquiriram conhecimento na formação inicial. Como defende Behrens (2007), a concepção que constitui a ação docente pode ser mudada ao longo do percurso profissional.

\section{CONSIDERAÇÕES FINAIS}

O objetivo deste trabalho consistiu em verificar quais são as consequências de uma experiência de formação colaborativa, nas concepções de professores acerca da abordagem das lutas nas aulas de Educação Física escolar. Inicialmente, identificamos que os docentes não se percebiam em condições de tematizar as lutas nessa disciplina por não se sentirem preparados, uma vez que julgavam não possuir conhecimento suficiente. Especialmente, porque não tiveram um componente curricular sobre a temática na formação inicial. Após a realização da investigação os resultados indicam que os docentes aprenderam mais sobre as lutas do que sabiam antes do estudo, particularmente em relação ao conhecimento conceitual. Mais precisamente, perceberam que é possível trabalhar com as lutas na escola pautados em classificações e aspectos universais dessa prática corporal. No mesmo sentido, compreenderam a importância de tratar das lutas numa perspectiva crítica e reflexiva.

Os principais elementos que permitiram a alteração de concepção dos docentes foram o estudo dos jogos de lutas e de sua classificação com base nas distâncias, a produção de tarefas e a vivência corporal durante os encontros. Esse conjunto de fatores permitiu entender que é possível o ensino das lutas na escola sem ter uma experiência como lutador em um esporte de combate específico.

Durante o processo de estudo, percebemos que o sentido atribuído pelos docentes aos assuntos estudados nos encontros está diretamente relacionado com o entendimento que possuem sobre o papel da Educação Física na escola. Com isso, conjeturamos que os professores farão diferentes usos do conhecimento adquirido com esse estudo. Para os docentes $\mathrm{A}$ e $\mathrm{C}$ o estudo serviu como uma possibilidade de desenvolver um tema de ensino através de determinados conteúdos conceituais ao ensinar lutas na Educação Física escolar, enquanto que para os educadores $B$ e $D$, constitui-se mais como um receituário de tarefas para aplicar com os alunos. Numa investigação futura, pretendemos analisar de que modo os professores utilizarão o conhecimento adquirido com essa formação continuada. 


\section{REFERÊNCIAS}

BEHRENS, M. A. O paradigma da complexidade na formação e no desenvolvimento profissional de professores universitários. Educação, Porto Alegre, v. 30, n. 63, p. 439-55, 2007.

BETTI, M. Educação física escolar: ensino e pesquisa-ação. 2.ed. Ijuí: Unijuí, 2013.

BETTI, M. Imagens em avaliação-ação: uma pesquisa-ação sobre o uso de matérias televisivas em aulas de educação física. Educar em Revista, Curitiba, n. esp. 2, p. 137-52, 2010.

BORGES, R. M. Diálogos sobre o ensino do esporte educacional: uma pesquisa-ação na formação continuada. 2014. 280f. Dissertação (Mestrado em Educação Física) - Universidade Federal do Rio Grande do Sul, Porto Alegre, 2014.

BRASIL. Ministério da Educação. Base nacional comum curricular: educação é a base. Brasília: Ministério da Educação, 2017. Disponível em: <http://basenacionalcomum.mec.gov.br/images/ BNCC 20dez site.pdf>. Acessado em: 10 de fevereiro de 2018.

BRASIL. Parâmetros Curriculares Nacionais: educação física. Brasília: Secretaria de Educação Fundamental, 1998.

CASTELLANI FILHO, L. Lino Castellani Filho: entrevista [Ago, 2011]. Entrevistador: Juca Kfouri. São Paulo: Canal ESPN, 2011. Entrevista concedida ao Programa Juca Entrevista. Disponível em: <https:// www.youtube.com/watch?v= 5CdwUpNqdg>. Acessado em: 9 de março de 2016.

CORREIA, W. R.; FRANCHINI, E. Produção acadêmica em lutas, artes marciais e esportes de combate. Motriz, Rio Claro, v. 16 n. 1 p. 1-9, 2010.

ESPARTERO, J. Aproximación histórico-conceptual a los deportes de lucha. In: VILLAMÓN, M. Introducción al judo. Barcelona: Hispano Europea, 1999.

GOMES, M. S. P. Procedimentos pedagógicos para o ensino das lutas: contextos e possibilidades. 2008. 139f. Dissertação (Mestrado em Educação Física) - Universidade Estadual de Campinas, Campinas, 2008.

GONZÁLEZ, F. J.; BRACHT, V. Metodologia do ensino dos esportes coletivos. Vitória: UFES, Núcleo de Educação Aberta e a Distância, 2012.

GONZÁLEZ, F. J.; FENSTERSEIFER, P. E. Entre o "não mais" e o "ainda não": pensando saídas do nãolugar da EF escolar I. Cadernos de Formação RBCE, Florianópolis, v. 1, n. 1, p. 9-24, 2009.

GONZÁLEZ, F. J.; FENSTERSEIFER, P. E. Entre o "não mais" e o "ainda não": pensando saídas do não lugar da EF escolar II. Cadernos de Formação RBCE, Florianópolis, v. 1, n. 1, p. 10-21, 2010.

GONZÁLEZ, F. J.; FRAGA, A. B. Afazeres da educação física na escola: planejar, ensinar, partilhar. Erechim: Edelbra, 2012.

HEROLD JUNIOR, C. Tradição e modernidade na pedagogia das lutas, artes marciais e esportes de combate: uma reflexão sobre o livro Ensino de lutas. Pensar a Prática, Goiânia, v. 19, n. 2, p. 501-4, 2016.

IBGE. Instituto Brasileiro de Geografia e Estatística. Pesquisa nacional por amostra de domicílios. Práticas de esporte e atividade física: 2015. Rio de Janeiro: Instituto Brasileiro de Geografia e Estatística, 2017.

LIMA, M. L. A abordagem das lutas nas aulas de educação física escolar: o que pensam os professores? 2018. 42f. Trabalho de Conclusão de Curso (Graduação em Educação Física) - Universidade Regional do Noroeste do Estado do Rio Grande do Sul, ljuí, 2018.

MATOS, J. A.; HIRAMA, L.; GALATTI, L. R.; MONTAGNER, P. C. Presença/ausência do conteúdo lutas na educação física escolar: identificando desafios e propondo sugestões. Conexões: Educação Física, Esporte e Saúde, Campinas, v. 13, n. 2, p. 117-35, 2015.

RUFINO, L. G. B. A pedagogia das lutas: caminhos e possibilidades. Jundiaí: Paco Editorial, 2012a.

RUFINO, L. G. B. “Campos de luta”: o processo de construção coletiva de um livro didático na educação física no ensino médio. 2012. 364f. Dissertação (Mestrado em Educação Física) - Universidade Estadual Paulista, Rio Claro, 2012b.

RUFINO, L. G. B.; DARIDO, S. C. A separação dos conteúdos das "lutas" dos "esportes" na educação física escolar: necessidade ou tradição? Pensar a Prática, Goiânia, v. 14, n. 3, p. 1-17, 2011. 
RUFINO, L. G. B.; DARIDO, S. C. 0 ensino das lutas na escola: possibilidades para a educação física. Porto Alegre: Penso, 2015.

SALDANHA, M. As lutas como tema de ensino na educação física escolar: uma análise da compreensão dos professores. 2018. 40f. Trabalho de Conclusão de Curso (Graduação em Educação Física) - Universidade Regional do Noroeste do Estado do Rio Grande do Sul, ljuí, 2018.

SILVERMAN, D. Interpretação de dados qualitativos: métodos para análise de entrevistas, textos e interações. Porto Alegre: Artmed, 2009.

THIOLLENT, M. Metodologia da pesquisa-ação. São Paulo: Cortez, 2011.

TRIPP, D. Pesquisa-ação: uma introdução metodológica. Educação e Pesquisa, São Paulo, v. 31, n. 3, p. 443-66, 2005.

ZEICHNER, K.; DINIZ-PEREIRA, J. E. Pesquisa dos educadores e formação docente voltada para a transformação social. Cadernos de Pesquisa, v. 35, n. 125, p. 63-80, 2005.

Autor correspondente: Robson Machado Borges

E-mail: robsonmachadoborges@gmail.com

Recebido: 28 de fevereiro de 2018.

Aceito: $\mathbf{2 1}$ de março de 2018. 